\title{
The switching principle of thyristor assistant arc extinguishing hybrid on-load tap-changer
}

\author{
Taoyuan $\mathrm{Cai}^{1}$, Xingying Zhao ${ }^{1}$, Fei $\mathrm{Shi}^{1}$, Benping Ding ${ }^{1}$, Pengfei $\mathrm{Jia}^{2,}{ }^{*}$, Luning $\mathrm{Hao}^{1}$, and \\ Lei Zhang ${ }^{1}$ \\ ${ }^{1}$ Shandong taikai Electric Power Equipment Co., Tai'an, China \\ ${ }^{2}$ China Electric Power Research Institute, High Voltage Research, Beijing, China
}

\begin{abstract}
Thyristor assistant arc extinguishing hybrid on-load tapchanger uses thyristor auxiliary mechanical switch which combines the advantages of mechanical switch and thyristor switch. The hybrid OLTC has high reliability, a relatively small amount of work needs to be maintained. It is a kind of very promising transformer OLTC. This project focus on the application of the hybrid OLTC in $110,220 \mathrm{kV}$ transformer, introduces the auxiliary thyristor arc hybrid on-load tap-changer principle of passive trigger with odd block switch to even block as an example, describes the hybrid on-load tap-changer switching process, and the switching principle of simulation verification, on the basis of summarizing the characteristics of hybrid on-load tap-changer.
\end{abstract}

\section{Introduction}

Auxiliary thyristor arc hybrid on-load tap-changer, retained the mechanical on-load tapchanger tap selector and switch, switch circuit increases the reverse parallel thyristor, by breaking the parallel thyristor to auxiliary machinery complete switch contact.After the completion of the parallel switching thyristor exit current-carrying loop, performed by mechanical contact load flow. In order to achieve the passive of thyristor trigger, on the basis of the research team at the early stage of the preparatory proposes a combined with existing KM tap-changer and hybrid on-load tap-changer switching principle of modified auxiliary thyristor arc hybrid on-load tap-changer switch principle, the scheme using three groups of basic circuit, thyristor can achieve the passive of thyristor trigger and withdrawal mechanism, and can make full use of existing KM type on-load tap-changer of other parts, advantages of low cost and good extensibility.

\section{Thyristor assistant arc extinguishing hybrid on-load tap- changer passive trigger principle}

\subsection{Passive triggered thyristor principle}

\footnotetext{
* Corresponding author: jiapengfei@epri.sgcc.com.cn
} 
Thyristor has the property of silicon rectifying device, is a kind of has three $p$-n junction four layer structure of high power semiconductor devices, can work under the condition of high voltage, high current, widely used in controlled rectifier, the ac voltage regulator, noncontact electronic switch, inverter and variable frequency electronic circuits.

Thyristor assisted mechanical contact action triggered passive principle as shown in figure 1, a pair of counter parallel thyristor at both ends of the mechanical switch, 1 and 4, 2, and 3, respectively is 2 of mechanical switch contacts, including 2 or 3 contact exists public side, as a trigger for thyristor trigger current, T1 and T2 for a pair of counter parallel thyristor module. As $\mathrm{AB}$ branch on mechanical contact action process for example: when the disconnect $\mathrm{AB}$ branch, cut off 2 to 3 contact, 2-3 action contact first contact in the disconnect instant small arc, arc established in 1, 4, end voltage, the voltage applied to the thyristor module on both ends of the anode and the corresponding thyristor door between anode and cathode, the formation of thyristor trigger condition, the role of the diode D1, D2, is this: if there is no D1, D2, after the thyristor conduction through the current of thyristor zero in natural reverse, will reverse current through the conduction of the thyristor cathode and gate to another counter parallel thyristor gate, circulation between the cathode, so the current will not be cut off, because of the thyristor gate between the anode and the cathode of the p-n junction J3 is very narrow, easily broken down. Current of thyristor conduction, is transferred to the thyristor branch, the first current passing zero thyristor switch off naturally, maximum conduction time is not more than half a cycle, when the design according to the half cycle time to consider, and considering the mechanical error control at about 12ms; Closed AB branch, 1-4 touch head closure, thyristor trigger conduction not, at this time, no arc, then the middle contact 2-3 closed, among them 2-3 after the close contact between the tap the voltage between the formation of the conditions of the thyristor conduction, trigger conduction thyristor, inhibition of contact between the discharge. Contact 2-3 closed completely after short circuit thyristor circuit, forcing thyristor turn-off, by mechanical contact load flow.

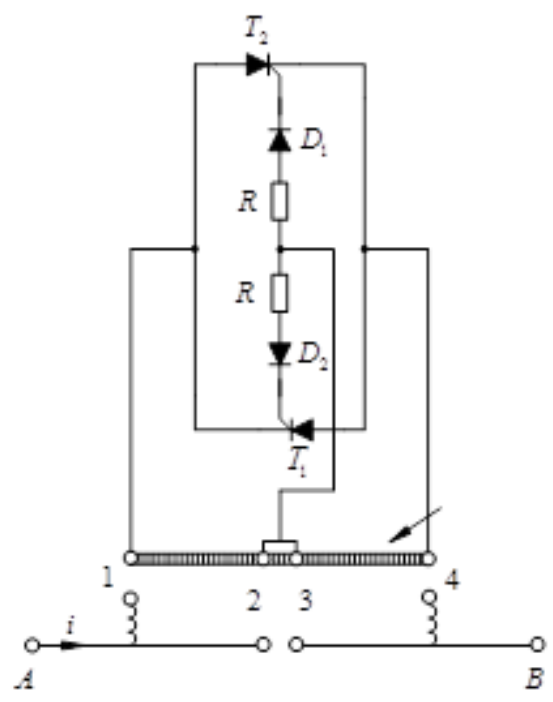

Fig. 1. The thyristor module in parallel.

Passive trigger this auxiliary thyristor arc has the following advantages:

(1) Do not need time control circuit switch action, by the scale to the realization of dynamic contact contact action sequence, complex electromagnetic interference problem has nothing to do with control circuit. 
(2) After the completion of the thyristor circuit switch out, don't load flow for a long time, can effectively reduce the loss of the thyristor state of extending the service life of the thyristor.

(3) The thyristor even out of control, mechanical switch can still play a role, will not damage the tap and transformer.

\subsection{The hybrid on-load tap-changer switching process}

Research of hybrid on-load tap-changer by principle of switch type is with existing KM (domestic combined $\mathrm{M}$ type modified) combine the principle of tap-changer formed as shown in figure 2 basic principles of the group from 3 thyristor module and basic circuit of double transition resistance. Double transition resistance basic circuit of a single basic circuit transition resistance advantages as follows: when the direction of the load change, there will not be because of a single resistor circuit switching is aggravating affect contact life can't even get to normal switch on-load tap-changer is caused by the fault phenomenon. Because when load changes direction, the sheet resistance of the circuit open circuit current and recovery voltage will be twice the rating, add greatly to switch between tasks, and adopts double transition resistance circuit can avoid this situation, a single transition resistance circuit does not apply to the existence of the represented by phase-shifting transformer power exchange contact transformer, and double transition resistance circuit applies to all transformer.

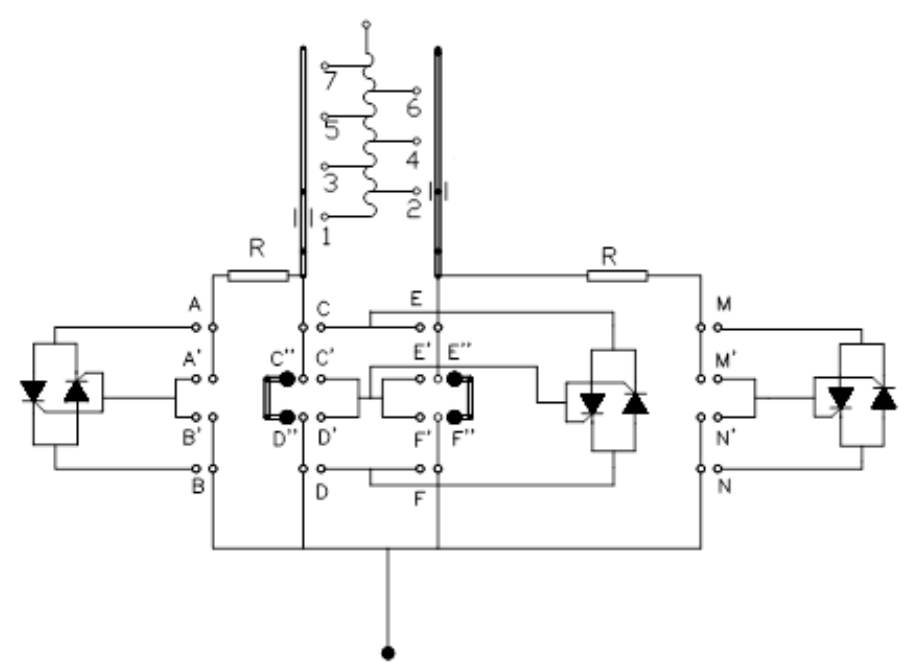

Fig. 2. Hybrid switch structure diagram.

Currently applied to the on-load tap-changer products maximum dynamic and static contact for corresponding to six guide groove, the increase of contact will increase guide groove number, reduce the insulation of the distance between contact, influence the insulation performance. Can be used in the hybrid on-load tap-changer is a guide to complete both dynamic and static contact of the sequential action, can solve the thyristor switch contact problem of quantity and complex fracture makes contact fracture into threedimensional layout, timing can be adjusted by the height of the adjustable spring.

Below in the odd gear switch to even as an example to analyze the process of gear, including $\mathrm{CD}$ and $\mathrm{EF}$ branch, $\mathrm{C}^{\prime \prime} \mathrm{D}^{\prime \prime}$ and $\mathrm{E}^{\prime} \mathrm{F}$, is the main contact other contactor is given priority to break a contact, $\mathrm{AB}$ and $\mathrm{MN}$ branch contact for transitional contact. Initial state closed C'D' and C"D" on the left side of the the main contact closure, CD branch flow, then 
the main contactor $\mathrm{C}^{\prime} \mathrm{D}^{\prime}$ open, closed $\mathrm{AB}$, after 10-12ms, $\mathrm{A}^{\prime} \mathrm{B}^{\prime}$ close, $\mathrm{C}^{\prime} \mathrm{D}$ ' open after $2 \mathrm{~ms}$, open the instantaneous arc trigger thyristor circuit, central conduction current from the $\mathrm{CD}$ back to pass A thyristor conduction, about $10 \mathrm{~ms}$ (depending on the action phase), current zero natural turn off thyristor, by $\mathrm{AB}$ branch current conduction. After $2 \mathrm{~ms}, \mathrm{CD}$ open, after about 3-5ms, MN closed, after about 6-8ms, M 'N' in the process of the closed trigger conduction on the right side of thyristor circuit, forming the bridge at this time. After about 2-3ms, M'N' completely closed, electricity flows through the $\mathrm{M}$ ' $\mathrm{N}$ ' conduction, thyristor circuit is short. After about $4 \mathrm{~ms}, \mathrm{~A}^{\prime} \mathrm{B}^{\prime}$ open, open the instantaneous arc trigger conduction on the left side of the thyristor circuits. After about $8-10 \mathrm{~ms}$, current zero thyristor arc naturally. Open after about 2-3ms, AB, AB opened about 3-5ms, EF together. After about $10 \mathrm{~ms}, E^{\prime} F^{\prime}$ in the process of the closed trigger thyristor in central conduction circuits. After about 2-3ms, E'F' completely closed, sub thyristor circuits. $\mathrm{M}^{\prime} \mathrm{N}^{\prime}$ open, open after about 8$12 \mathrm{~ms} \mathrm{MN}$, then $\mathrm{E}^{\prime} \mathrm{F}^{\prime} \mathrm{E}^{\prime \prime} \mathrm{F}^{\prime \prime}$ on the right side of the main contact close, switching process to complete a full at this time.

\section{Thyristor assistant arc extinguishing hybrid on-load tap- changer switching principle of the simulation}

Research on hybrid on-load tap-changer in switch action contact open circuit and closed when the action sequence key problems, such as using Mayr arc model in further hybrid onload tap-changer microtek thyratron passive principle and working process of the switch trigger made the simulation analysis.

As shown in figure 3 for $110 \mathrm{kV}$ hybrid on-load tap-changer, under the load current is 600 a simulation of thyristor trigger current flow, in which (a), (b) to get under two different open circuit phase four trigger condition, by the simulation results, thyristor after the first and third trigger conduction, shut off by means of current natural zero passage, and the second and the fourth the trigger conduction, after roughly $1 \mathrm{~ms}$ are bypass contactor short-circuit turn off, and under the different open circuit phase, thyristor to import electricity flow in different sizes.

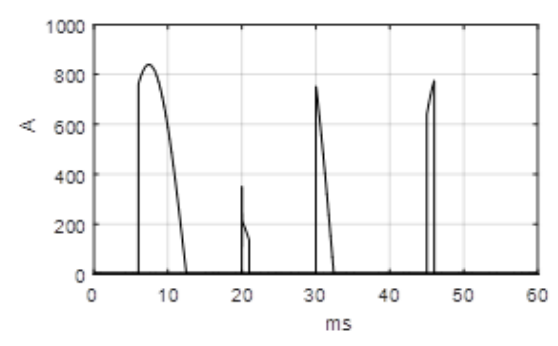

(a)

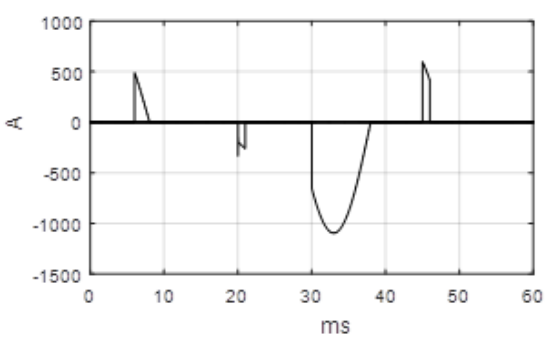

(b)

Fig. 3. Thyristor trigger under 600A load current.

By this section of the hybrid on-load tap-changer thyristor trigger and the working process of the switch of the results of simulation, the hybrid on-load tap-changer in contactor switch process microtek thyratron trigger conditions consistent with the designed, triggering the total four times, twice the corresponding contact open circuit when triggered, and the current natural zero shut off, two corresponding trigger when contact is closed, and the bypass contactor short circuit, by shut off, thus proves the working principle of the hybrid on-load tap-changer is feasible. Due to arc affected by the speed of the transformer oil, temperature, and the size of the open circuit when the current, and the corresponding the influence of some factors on the size of the recovery voltage, therefore the simulation 
using Mayr arc model does not accurately the situation of the development of the electric arc simulated, so on the working principle of hybrid on-load tap-changer is verified on the basis of simulation analysis also need to be further studied.

\section{Conclusion}

Hybrid on-load tap-changer on-load tap-changer with mechanical and electrical power electronic on-load tap-changer, compared with the following features:

(1) It uses electric power electronics auxiliary mechanical contactor switch, switch process in micro arc phase transition can be realized only branch diversion, greatly reduces the switch performance degradation in the process of transformer insulation oil, can reduce the number of oil filter and oil change, increase the service life of switch.

(2) After the completion of the power electronic devices to exit the current-carrying loop, by mechanical contact load flow, reduce the loss caused by power electronic device conduction for a long time, avoids damage because of the power electronic device switch caused by low reliability, prolong the service life of on-load tap-changer.

(3) Hybrid on-load tap-changer also has shortcomings, it effectively solves the mechanical switch on-load tap-changer process produce arc problem, but did not solve the mechanical on-load tap-changer is the problem of low response speed compared with the power electronic type on-load tap-changer, switching speed slower.

\section{References}

1. Faiz J, Siahkolah B. New solid-state on load tap-changers topology for distribution transformers [J]. IEEE Transactions on Power Delivery, 2003 18(1): 136-141.

2. Jipping J E, Carter W E. Application and experience with a $15 \mathrm{kV}$ static transfer switch [J]. IEEE Transactions on Power Delivery, 1999, 14 (4): 1477-1481.

3. Harlow JH, Stich F A. An arcless approach to step-voltage regulation [J].IEEE Transactions on power apparatus and systems, 1982, 101 (7): 2096-2102.

4. D.Gao. 2002 “A novel thristor assited diberter switch for a solid-state tap changer" , Transmission and Distribution Conference and Exhibition 2002: Asia Pacific. IEEE/PES, Vol. 1, pages297-300.

5. Gómez-Expósito, Bachiller-Sloer. A lab setup illustrating thyristor-assisted under-load tap changers [J]. IEEE Transaction on Power Systems, 2010, 25(3): 1204-1210.

6. Monroy-Berjillos D, Gomez-Exposito A, Bachiller-Soler A. A lab setup illustrating thyristor-assisted under-load tap changers [J]. IEEE Transactions on Power Systems, 2010, 25(3): 1203-1210. 